\title{
Hacia una retórica y una poética del silencio**
}

\author{
From a rhetoric and a poetics of Silence
}

Rumo a uma retórica e poética do silêncio

\footnotetext{
* Profesor de tiempo completo del Departamento de Humanidades en la Universidad Tecnológica de Pereira. Licenciado en Español y Literatura y magister en Literatura de la misma Universidad. Actualmente adelanta estudios de doctorado en Literatura en la Universidad Tecnológica de Pereira. Ganador del concurso Colección de Escritores Pereiranos en la modalidad ensayo en el año 2012 con la obra Esa delgada luz que es el silencio. Correo electrónico: rave@utp.edu.co

** Este artículo hace parte del proyecto titulado Conciencia y escritura del silencio en la narrativa breve de Felisberto Hernández, Francisco Tario y Efrén Hernández, el cual se presentó como requisito para optar al título de magister en Literatura en el año 2012 y se integra con la propuesta de investigación doctoral Decir lo indecible. Poética del silencio para la narrativa breve hispanoamericana. Artículo de investigación recibido el 31/o8/2015 y aceptado el 17/o8/2016.
} 


\section{Cómo citar}

RAMÍREZ RAVE, J. M. (2016). Hacia una retórica y una poética del silencio. Revista CS, no. 20, pp. 143-174. Cali, Colombia:

Facultad de Derecho y Ciencias Sociales, Universidad Icesi.

DOI: http://dx.doi.org/10.18046/recs.i20.2052 


\section{Resumen}

Abstract

Resumo

El presente trabajo plantea un análisis de la retórica y la poética del silencio, desde una perspectiva que asume la retórica como aquellos procedimientos y recursos usados por el autor para escribir y hacer oír el silencio en su obra. Mientras busca demostrar que la poética del silencio va más allá de una postura ante el lenguaje que se manifiesta en la escritura de algunos recursos retóricos o gramaticales. En este sentido la poética se presenta como la fuente misma de la que mana la escritura, es un acto consciente, una necesidad por escribir aquello que no se puede decir.

PALABRAS CLAVE:

silencio | retórica | poética | literatura hispanoamericana

The following assay presents an rhetoric examination and the poetics of silence, from a perspective that assumes the rhetoric as those procedures and methods used by the author to write and hear the silence in his authorship,while it seeking to demostrate that the poetics of silence goes beyond further on the language that appears in the writing of some rhetorical or grammatical resources. In this sense, poetry is presented as the very source of flowing writing, as a conscious act, a necesity to write what can not be said.

\section{KEYWORDS:}

Silence | rhetoric | poetics of silence | Hispano-American Literature

Este trabalho apresenta uma análise da retórica e poética do silêncio a partir de uma perspectiva que assume a retórica como os procedimentos e os recursos utilizados pelo autor para escrever e fazer ouvir o silêncio em seu trabalho, ao mesmo tempo que visam demonstrar 
que a poética do silêncio vai além de uma posição sobre a língua que se manifesta na escrita de alguns recursos retóricos ou gramaticais. Neste sentido, a poética apresenta-se como a própria fonte da qual emana a escrita, é um ato consciente, uma necessidade de escrever aquilo que não pode ser dita.

\section{PALAVRAS CHAVES:}

Silêncio | retórica | poética | literatura hispano-americana 
Más tarde aún, descenderá el silencio, suave, paulatinamente, como con paracaídas. Y cuando el silencio se tienda a reposar sobre la tierra, de la más grande y pálida de todas las estrellas brotará una canción.

EFRÉN HERNÁNDEZ, «Unos cuantos tomates en una repisita»

\section{A manera de introducción}

El presente trabajo se presenta como punto de partida para la construcción de una poética del silencio para la narrativa breve hispanoamericana. Por esa razón se plantea la lectura, revisión y posterior adaptación de diferentes teorías que sobre las claves de la poética, la estética, la estilística y la retórica del silencio han sido rastreadas casi exclusivamente para la poesía. En este sentido, parece que existen marcadas diferencias entre las apuestas teóricas y prácticas de esta estética asociada a la poesía y la forma como algunos narradores hispanoamericanos manifiestan una plena conciencia y escritura del silencio, esto se da porque dichos autores en sus obras han acuñado una serie de procedimientos expresivos propios del campo narrativo.

De tal forma que para construir dicha poética del silencio se debe trazar un recorrido que: primero, realice un análisis de los recursos estilísticos y retóricos que algunos autores utilizan en su afán por escribir el silencio. Segundo, que examine ciertos rastros dejados en los textos, los mismos que sirven de evidencia para constatar una profunda reflexión sobre la capacidad y la incapacidad de la palabra creadora, lo que finalmente implica el reconocimiento de la conciencia que algunos escritores han tenido del silencio, en la medida que sus obras circundan los límites del lenguaje.

\section{Silencios...}

¿Al principio era el logos?

Salvo matices, como bien lo apunta André Neher (1997: 62), tanto Filón y san Agustín, como Maimónides y Leibniz, Kepler y Pascal, coinciden en la lectura bíblica cuya premisa reza: en el comienzo era la Palabra, es decir, que efectivamente - para ellos que encabezan una larga lista en la tradición Occidental ${ }^{1}$ - al principio sífue el Logos, un logos

1. Respecto de la afirmación que en el comienzo era la Palabra, André Neher dice que esta no es: «[...] patrimonio exclusivo del cuarto evangelio, sino que el más popular de los intérpretes judíos de la Biblia, Raši de Troyes, la presenta, en la Edad Media, con una seguridad ingenua, desde las primerísimas líneas de su comentario de la Torah» (Neher, 1997: 62). 
que no es solamente medida de la razón, sino también el Verbo, la Palabra. Bajo esta mirada no existe un lugar para el silencio: Todo está cubierto por la palabra².

En el mismo sentido, la teoría literaria atendió con obstinada frecuencia las zonas centrales de las obras, aquellas zonas que por lo general están llenas de palabras 3 , sin ocuparse del margen, de los silencios, como si estos fueran la negación de lo literario; pero «si la creación literaria es el arte de la palabra, ¿cómo puede haber un silencio literario? y ¿cómo puede la teoría literaria hablar de lo que no está en el texto literario?» (Bobes, 1992: 100). Las respuestas a estas y otras preguntas empiezan a vislumbrar nuevos horizontes de sentido en la medida que la teoría literaria adopta nuevas perspectivas de análisis para desvelar las zonas marginales que antes estaban relegadas a un segundo plano.

Entonces... ¿Al principio era el silencio?

El silencio se abre paso entre las palabras para iluminarlas. Gracias a él, en el papel, el canto del ave se hace canto. La palabra nace del silencio, porque el silencio sopla entre los espacios blancos. La pausa hace el poema, de allí que los espacios permitan que las palabras se deslicen hacia el abismo de la significación. El silencio es el cimiento, tal vez, es la respuesta que Roberto Juarroz buscaba cuando en su Cuarta Poesía Vertical dice: «Las palabras son pequeñas palancas,/ pero no hemos encontrado todavía su punto de apoyo» (2008: 95). Entonces, tal como lo anticipa el poeta argentino frente a las palabras:

2. La cultura occidental se caracteriza por un miedo y un rechazo al silencio profundamente arraigados a su psicología, producto - en muchos casos- de la tradición mitológica y religiosa. En Occidente se hace necesario romper el silencio para que el mundo pueda existir, sin la destrucción del silencio el vacío informe y desprovisto de significado sigue su reinado (tanto cristianos como islamistas aprendieron del judaísmo que en el principio de la historia de la creación no había nada). Palabra y sonido son génesis, creación. Dios nos creó hablando así en el principio «[...] Dios dijo: "Hágase la luz”, y la luz se hizo». Al brotar la palabra surgió también el silencio, su opuesto. Por tal motivo, todo silencio aguarda el momento de romperse. De igual forma, entre la cultura greco-romana existieron divinidades y referentes mitológicos vinculadas al silencio; pero en la mayoría de los casos asociados a un carácter restrictivo, impositivo, marginal, oscuro, sancionatorio, entre otros aspectos negativos. Algunos de los ejemplos más representativos son los del dios Harpócrates «(...) el que reprime la voz y ordena silencio con el dedo»; la silenciada divinidad de los muertos Tacita Muta, las tres locuaces Minieidas, el indiscreto Ascálafo, espía de Plutón, y la divinidad asociada a la angustia y el miedo, Angerona. Para un completo y pormenorizado análisis del tema se recomienda la obra Viaje al silencio de Sara Maitland, particularmente el capítulo número 4, titulado «El silencio y los dioses».

3. Desde mediados de los años setenta, como afirma Carmen Bobes Naves (1992: 99), se va perfilando en la literatura o en teoría literaria el silencio como posible signo lingüístico a la vez que como signo literario, desplazando parcialmente la centralidad que hasta el momento se le había otorgado a la palabra. Lo anterior, coincide con Ascensión Rivas Hernández, cuando en su trabajo De la poética a la teoría de la literatura. (Una introducción) dice que en los años 60 cayeron en declive las distintas teorías desviacionistas: el formalismo, el estructuralismo, el concepto jackobsoniano de la función poética, la teoría de los coupling formulada por Levin, la connotación, etcétera. 


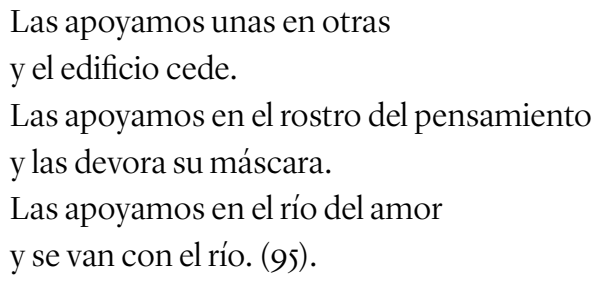

Aquella voz que surge del poema nos advierte que la palabra no debe nacer del ruido contaminante de otra palabra, porque ese edificio frágil que es el lenguaje terminará por derrumbarse ante la debilidad de las palabras huecas, igual sucede cuando las enfrentamos al pesado rostro del pensamiento, porque reducirlo todo al dominio del concepto, a los límites del significado, es despojarlas del misterio que cada una entraña, finalmente llama la atención para que no dejemos que su liviano cuerpo se sumerja en el falso fulgor de la palabrería sin control.

En este sentido, el punto de apoyo de las palabras bien puede ser el silencio; «pero seguimos sin saber qué queremos levantar» (95) con las palabras: ¿La vida? ¿La muerte? ¿El hecho mismo de hablar? ¿El círculo cerrado de ser hombres? Esta es la naturaleza de la pregunta a la que se enfrenta el escritor, el narrador, el poeta.

Pero, al igual que Juarroz, no debemos entender el silencio como mero espacio en blanco, espacio que gravita entre el ritmo y el sentido o como un elemento menor cuya única función es dotar a las palabras de los énfasis necesarios para ser significativas. Reducirlo a esto, es convertirlo en ornamento, alienación de una palabra, epifenómeno, tímido residuo. Es reducirlo a un modo de hablar sin palabras, a un elemento menor siempre subordinado al protagonismo de las desgastadas palabras, una metástasis de ellas, pues el silencio - bajo esta óptica - carece de existencia en sí mismo, aun llegando a ocupar un lugar privilegiado parece no tener una cualidad ontológica propia.

Tampoco debemos verlo como un opuesto de la palabra ${ }^{4}$, siendo lo Otro comparte el mismo origen. Porque «La palabra y el silencio son una sola cosa: la palabra está hecha de silencio. Al igual que el silencio está hecho de palabra» (Picard, 1971). El silencio

4. Ya en los trabajos que anteceden esta propuesta: Conciencia y escritura del silencio en la narrativa de Felisberto Hernández (2010) y Esa delgada luz que es el silencio. Aproximaciones a la escritura del silencio en la literatura latinoamericana (2012) se desarrolla el tema de la relación palabra y silencio que sin ser entidades comparables, no quiere decir que sean incompatibles, lejos de esto, la una evoca a la otra. Al respecto se propone: La palabra nace del silencio, de ahí que el silencio puede existir sin la palabra, pero no la palabra sin el silencio y sin embargo sólo es a través de la palabra que este recibe sentido y dignidad. El silencio es cimiento, salvaje depositario, seno de la palabra, su existencia es paralela. Lejos de negar su valor, el silencio custodia su belleza, la protege del ruido que intenta atraparla, poseerla en los dominios del concepto. Palabra y silencio, dice Colodro forman «(...) parte de un mismo universo, de un mismo ámbito de expresividad y significación, tal como el sinsentido puede formar parte del sentido, de su naturaleza ambigua y polivalente» (2004:14), para este autor el silencio se puede mirar como lo Otro de la palabra, como una alteridad que comparte sin saberlo el mismo origen. 
es el preludio, depositario y en él descansa la palabra antes de alzar un nuevo vuelo. El lenguaje es continuo, el silencio no interrumpe el habla, la hace posible.

Por eso aquí se atiende a una forma de entender el silencio que subvierte la propia semántica, al tiempo que se señala una pulsión (en el arte en general, particular en la literatura) positiva e intencional que separa al silencio de la tradicional percepción abstracta que se tiene de él para transformarlo en una acción o hecho que transita los límites de la renuncia pero que no cede ante ella. Se busca denotar un silencio que es presencia y extrañamiento. Un silencio que lejos de la ausencia o la carencia, del déficit o falta de sonido, del habla o del ruido nos entrega múltiples voces, susceptibles de ser analizadas si aceptamos mirarlo, escucharlo... a partir de su propia naturaleza abisal. El silencio así entendido se convierte en una poderosa metáfora del cambio de paradigma. Se convierte en una invitación al cambio, en la medida que nos muestra una vía de escape a las propuestas limitadoras de una tradición que ha visto en el silencio el lado oscuro, la máscara, la carencia y el peligro. Por el contrario el silencio es camaleónico, polisémico y en sí mismo es la negación de lo absoluto.

Hablar del silencio en la literatura - en las artes en general-, con el paso de los años se ha convertido en un territorio común. Son conocidos los casos de aquellos autores que deciden suspender su labor creativa entregando sus palabras al absoluto silencio. Estos bartlebys, entre los que podemos contar a Arthur Rimbaud, J.D. Salinger, Racine, Pepín Bello, Carmen Laforet, Juan Rulfo y Santiago Davobe, entre otros, son dignos representantes del denominado síndrome del silencio, de la escritura del No; como salidos del cuento de Melville, prefieren no hacerlo, es decir, prefieren no seguir escribiendo. En este mismo sentido se ha escrito sobre la angustia que produce la página en blanco.

Otros ven en el silencio un tema para su escritura; creen que al nominarlo, que al escribir la palabra silencio y sus variantes, conjuran el problema del arte contemporáneo, en donde al artista paradójicamente, como lo expresa Susan Sontag, le faltan las palabras y las tiene en exceso, en la medida que «el lenguaje es el más impuro, el más contaminado, el más agotado de todos los materiales que componen el arte» (1985:23). Bajo estas circunstancias se debe diferenciar entre aquellas obras que escriben sobre el silencio y aquellas que por sus búsquedas se constituyen en obras silenciosas. Debemos diferenciar entre aquellos que sucumben ante él, aquellos autores que sólo se jactan de conocer los temas que los inscriben y quienes con plena consciencia lo escriben. Es decir, tal como lo propone Ramón Pérez Parejo debemos establecer una distinción taxativa entre «hablar del silencio»y «hablar desde el silencio», ya que «"Hablar del silencio" es una temática y puede abordarse desde cualquier estilo. "Hablar desde el silencio" es abordar cualquier tema (aunque haya algunos más afines que otros), incluso el tema del silencio desde una determinada estética, en este caso desde la estética del silencio» (2013:26). 
De allí que el camino que aquí se emprende busca ponderar obras literarias silenciosas, más no aquellas que por algún motivo fueron silenciadas, entendiendo que tanto la misma crítica, un público con escaso sentido crítico y artístico, al igual que la constatación de que el hecho literario se ha convertido en un espectáculo artificioso y banal, corrompido por el ruido, el dinero y las leyes del mercado editorial, han ayudado para que muchas obras terminen bajo el polvo que se acumula en los anaqueles de las literaturas nacionales.

Dentro de este marco es que podemos hablar de obras que son silenciadas; pero para nuestra fortuna «En general, los libros son, desde luego, menos finitos que nosotros» (Brodsky, 1992: 383) y cuando tomamos y damos vueltas en nuestras manos a estos objetos rectangulares, acariciamos, - en el amplio sentido del tacto, como modalidad sensorial que integra nuestra experiencia del mundo con la de nosotros mismos- «con nuestros dedos, como tal, las urnas reales o potenciales con las susurrantes cenizas de alguien» (384).

\section{Hacia una retórica y una poética del silencio}

El silencio ha alcanzado gran importancia en las distintas esferas de la reflexión cultural, prueba de ello es la variedad, profusión y proliferación de bibliografía dedicada al tema, así como un manifiesto interés por abordarlo y definirlo de acuerdo con sus propias categorías conceptuales y metodológicas. Desde la filosofía del lenguaje (Wittgenstein, Russell, Max Colodro, Javier Muguerza), el psicoanálisis (Freud, Reik, Morgenstern, Fliess, Lacan, Kristeva), la sociología (Peter Burke, Edward T. Hall), y la semiótica (José Luis Ramírez, Rogelio Tobón), hasta la literatura (Blanchot, Paz, Nuria Amat), el feminismo (Irigaray, Cixous, Enna Castillo Montero), y las religiones (Paul Fenton, Óscar Pujol, Shizuteru Ueda, André Neher, Alfonso Álvarez) pasando por las reflexiones multidisciplinarias de Foucault, Barthes, Steiner, Sara Maitland, Ramón Xirau y David Le Breton, el silencio ha generado un abundante material de reflexión cuya riqueza exige aproximaciones plurales.

Se parte entonces de la convicción de que escribir sobre el silencio, no deja de ser una contradicción. Porque para hacer conocer, para plantear, el silencio que nos ocupa, debemos hablarlo - escribirlo- en algún momento. Hablarlo, no quiere decir encasillarlo en un concepto. El silencio - tal como aquí se entiende- no se deja encasillar. Le es esquivo al concepto, a la ciencia, a una disciplina. Su naturaleza es ambigua, por eso no se deja asir. $\mathrm{Su}$ «espíritu es transdisciplinario», porque invita a la transgresión, al ir más allá de toda disciplina. 
Kovadloff, en su obra El silencio primordial, advierte de las exigencias y necesidades que plantea un estudio dedicado o cuya base sea el silencio, de ahí su carácter transdisciplinar. Por tal razón, el presente trabajo se presta especialmente para la heterogeneidad de enfoques, si tenemos en cuenta que la literatura ha sido un espacio privilegiado para poner en escena discusiones relacionadas con el silencio. Podemos aventurar un recorrido que en vez de negar, potencia la importancia de los desarrollos disciplinarios, a través de diálogos y convergencias. De allí, y haciendo honor a la vitalidad del prefijo «trans», que se deba hacer un movimiento «entre», «a través de»y «más allá» de las disciplinas para poder dar una respuesta integradora, jamás concluyente, al tema de la conciencia y escritura del silencio en el vasto mundo de la narrativa breve hispanoamericana.

Sólo así podemos trazar un recorrido que primero parta del examen de los recursos retóricos y estilísticos que los autores utilizan para escribir el silencio. Segundo, que analice los rastros dejados en sus textos para evidenciar la reflexión de la capacidad y la incapacidad de la palabra creadora, lo que finalmente implica una revisión de la conciencia que los escritores tienen del silencio, en la medida que sus obras circundan las fronteras de la palabra, es decir, los límites del lenguaje.

Característica que ubica a un grupo diverso de narradores y poetas como representantes de esa manifestación del pensamiento filosófico y artístico surgida de la crisis general del lenguaje, de la palabra, que primero Susan Sontag (1985) y luego Amparo Amorós (1982) denominaron «estética del silencio». En definitiva, realizar este recorrido para constatar la presencia de este fenómeno, de una consciencia plena, cuya presencia sirve de base a su forma de expresión y a su propia concepción como forma artística, implica una aproximación plural, respuestas integradoras, lo cual sólo es posible a través de la observación y el descubrimiento de nuevas formas de percepción y valoración.

Por último, tal como lo ha planteado Eduardo Chirinos, en la actualidad no existe «una tipología que sistematice y describa las distintas maneras de presentación y representación del silencio, en la poesía hispanoamericana de la segunda mitad del siglo $[X X] »(1998: 26)$, en nuestro caso, tampoco existe dicha tipología para la narrativa breve de hispanoamericana. Chirinos subsana dicha ausencia en su trabajo con la revisión y ampliación de tres propuestas paradigmáticas, la de Rae Armantrout en su ensayo «Poetic Silence» (1985) en la que se revisa el poder autorial que regula y determina la inclusión del silencio en el poema; la de Lisa Block de Behar con su estudio «Una retórica del silencio» (1994), en la que se analizan las funciones y la participación del lector sobre ese «objeto silencioso» en el que se constituye la obra literaria y, finalmente, la propuesta de Amparo Amorós en su trabajo «La retórica del silencio» (1982), en la que se presentan los diversos recursos expresivos que genera el silencio para hacerse oír en un texto. 
Atendiendo a la naturaleza del estudio que desde hace algunos años se ha iniciados, el cual busca evidenciar la conciencia y la escritura del silencio en obras de narradores hispanoamericanos, se subsanará la ausencia de una tipología a partir de una serie de propuestas emparentadas con la retórica, la estilística, la poética y la estética del silencio, siendo el objeto del presente artículo desarrollar particularmente aquello que constituye la retórica y la poética del silencio.

\section{Hacer oír el silencio en la literatura}

Hablar de una retórica del silencio implica partir de la actualidad de esta disciplina en las últimas décadas. Es decir, en primer lugar, se debe trascender el plano tradicional que la considera como una teoría de la elocución (ocupada del embellecimiento de los pensamientos) o un mero adorno del discurso, para ubicarla -según lo propone Claude Bremond (1976) - como una dimensión esencial de todo acto de significación. En este sentido, el aporte que realiza Benedetto Croce (1997) al constatar la confusión entre arte y técnica es fundamental, ya que nos muestra la reducción moderna de la retórica a una simple técnica, a una teoría del ornato, en la que se reduce el lenguaje a téchnē, desvinculando la forma del contenido. El resultado: la retórica como un mero inventario de figuras estilísticas.

En segundo lugar, y siguiendo a Michel Charles, la retórica no puede constituirse sino a partir de la poética. No existe una retórica sin poética y, a la inversa, no se debe pensar en una poética sin retórica. En este punto se puede considerar la propuesta de Croce que para Mauricio Beuchot y Francisco Arenas-Dolz busca «la unificación de retórica, poética y estética ${ }^{6}$, en una dirección semejante a la señalada por Vico, quien identificaba lenguaje y poesía, es decir, intuición y arte, superando la dualidad sujeto-objeto. Así, Croce, al liquidar el estatuto del lenguaje en tanto que téchnē, trata de resolver estéticamente el problema de la relación subjetividad-objetividad» (2008:211).

En esencia, la retórica es aquí percibida como una ciencia general de la comunicación y de la expresión lingüística, es decir, del expresar. Tomando el término expresión de la antropología y de la estética, sobre todo de la estética, en la cual no funciona como algo estático, sino dinámico, como una manifestación del ser íntimo del hombre. La expresividad es, en todo caso, una característica inseparable del lenguaje. Dicha concepción de la retórica como ciencia de la expresión humana entra en diálogo con

5. Ver nota 1.

6. En lo que respecta al silencio: poética, retórica o estilística del silencio, son denominaciones que pueden ser consideradas — en el caso de Bobes Naves (1992) - como sinónimas para una etapa poética que se inicia aproximadamente en los años setenta. Amparo Amorós (1991), por su parte, utiliza el término «poética del silencio» para los inicios de este período y «retórica del silencio», en un sentido claramente despectivo. 
aquello formulado por Croce y Collingwood cuando afirman que el arte y el lenguaje son lo mismo, dos modos de expresión. Al respecto Beuchot y Arenas-Dolz realizan la siguiente interpretación:

El arte es expresión de los sentimientos humanos. El término «expresión» puede referirse tanto a un proceso emprendido por el artista como a una característica del producto de ese proceso. La teoría del arte como expresión implica pues, tanto en Croce como en Collingwood, una teoría relativa a lo que el artista siente y emprende cuando crea una obra de arte. (Beuchot y Arenas-Dolz, 2008: 209).

Bajo estas circunstancias, forma y contenido operan como una unidad, a la vez que se le concede una orientación estética a la lingüística. La retórica pasa a ser «una "ciencia de la palabra", no de las palabras, una "ciencia del hablar", de la actividad lingüística, y no de su mero instrumento. La palabra -el lenguaje-es la actividad lingüística, las palabras son el instrumento material de esa actividad» (Beuchot y Arenas-Dolz, 2008: 212-213).

Sin embargo, hablar de una retórica del silencio nos obliga a ocuparnos tanto de la actividad expresiva de la palabra (como «facultad» y como «actividad»), como del silencio, que, al formar parte del mismo universo de la palabra, comparte un idéntico ámbito de expresividad y significación. El silencio despliega una singular potencia expresiva, potencia que para autores como Amparo Amorós, Santiago Kovadloff y Marcèl Rius crece por oposición a la elocuencia y grandilocuencia verbal.

No se tiene como único objetivo mostrar una «gramática del silencio», si se permite el uso del término, sino que a partir de la reivindicación que Croce ha hecho del principio de expresión como unidad de forma y contenido, se busca desvelar el valor cognitivo de la retórica del silencio, es decir, presentar a las figuras y tropos de la retórica clásica vinculados al silencio, no como un catálogo o meros «caprichos del placer» de la escritura, sino como necesidades de la mente en su permanente búsqueda por enseñar el sentir interno del ser humano.

Cabe resaltar que diversos críticos han tratado el tema de una retórica del silencio en la literatura hispánica, principalmente en autores del Siglo de Oro. Para nuestro continente el referente más remoto se encuentra en la literatura de sor Juana Inés de la Cruz, en la medida que su obra, «constituye un discurso verdaderamente paradigmático en el cual, a la vez que se utilizan, transforman y redimensionan los modelos dominantes, se generan las bases de una nueva retórica donde es la manipulación del silencio, tanto como de la palabra, la que está en la base de la persuasión y la elocuencia» (Moraña, 1998: 155). Sin embargo, como se ha dicho, no existe una tipología que sistematice y describa las distintas maneras de presentación y representación del silencio, ni para la poesía ni para narrativa breve del continente.

De tal forma, y con la pretensión de no caer en reduccionismos, conviene trazar un camino para explorar las distintas maneras en que el silencio se introduce en el texto 
(obra literaria) y lo articula. Es decir, cuáles son los procedimientos y recursos usados por los escritores para escribir y hacer oír el silencio.

\section{El silencio en la literatura}

Carmen Bobes Naves (1992) centra su atención en qué son los silencios, es decir, algunos tipos (taxonomía rápida: silencios textuales y del subtexto) y las formas de silencios en la literatura (cómo son los silencios literarios). Entre los silencios textuales se encuentran aquellos que el autor introduce en la obra como tema o como recurso: el silencio en el texto como contraste; el silencio relativo de los temas relegados a zonas marginales; el silencio de un texto que no refleja códigos y marcos exteriores como cabe esperar de sus partes y disposición.

En cuanto al silencio del subtexto, este se caracteriza porque gracias a él, lo que se dice (referencia orientadora de lectura) y lo que no se dice (signo literario en contraste con lo que se dice) puede ser interpretado de varias maneras, en lecturas diversas, según el horizonte de expectativas en que pueda situarse el lector.

Entre las formas como se manifiestan los silencios en la literatura, la profesora Bobes Naves destaca: el silencio como tema (hablar del silencio), lo que la autora considera como su retórica; el silencio de los códigos, lo que nos ubica en aquellos silencios que proceden del sistema sémico y, finalmente, nos presenta un denominado silencio esquemático. Podríamos sintetizar la propuesta de Bobes, en relación con una tipología de silencios literarios, en los siguientes aspectos:

\section{Tipos de silencio «literario»}

\section{El silencio como contrapunto textual}

Se caracteriza porque se distribuye en alternancia con la palabra en el discurso de todo el texto. El silencio literario se toma aquí como blanco constitutivo de la obra, en concurrencia con la palabra. En este sentido, en el arte literario el silencio toma su ser de la palabra latente, allí se dispone a tener sentido no sólo por el contrapunto en que ambos están situados de un modo inmediato, sino en el conjunto de un texto. En cuanto al mundo de la reflexión y de la teoría literaria, en la medida que los silencios confieren sentido al texto, se ha planteado la necesidad de interpretarlos como signos lingüísticos, a su vez, el acceso a la pragmática hace posible la lectura de los silencios como signos literarios, de allí su carácter no sistemático y contextual.

Al ser los silencios interpretados como un signo literario, es decir, al no poseer un carácter sistemático se presentan en concurrencia con otros signos circunstanciales, 
cuyo sentido varía de un texto a otro y, por tanto, su interpretación se debe realizar en el contexto de la obra analizada, es decir, en el espacio que ocupa en el texto que lo acoge y lo crea.

\section{El silencio espacial}

Es un tipo de silencio parcial de los temas relegados a un lugar secundario del texto. Este tipo de silencio fue descubierto por la teoría literaria, pero en la actualidad se vincula fuertemente con la filosofía. Se caracteriza porque introduce contenidos (sobre el sujeto emisor del mensaje o sobre los sistemas culturales envolventes) en el texto de forma indirecta por medio de signos que son testimonio de temas latentes, de motivos que por diversas razones son silenciados en el discurso. Partiendo de los deconstructivistas quienes centraron el interés de la crítica hacia los temas marginales del texto, se logra reclamar un orden de lectura y organizar una interpretación que ubica estos temas en el centro semántico. Dichos temas son acogidos por los márgenes, los comentarios, las notas a pie de página, los excursos, entre otros.

En todo caso, el escritor - voluntaria o involuntariamente-deja en el texto huellas viscerales, signos e indicios, que hablan de sus propios silencios y que quedan ocultos en su escritura, pero cuyo reconocimiento sólo es posible cuando se hace una consideración pragmática de la obra, en tal sentido un análisis de tipo estructural o estilístico sólo dará cuenta de lo que hay en el texto sin advertir la expresión de silencios espaciales (marginales).

\section{El silencio estructural:}

Se advierte desde un esquema con el que se pone en relación el texto (silencio emitido o recibido). Gracias, por ejemplo, a la pragmática la obra se puede situar como parte de un proceso, de esta manera se logran establecer las diversas relaciones externas del «producto» con otros sistemas envolventes, llegando así a descubrir, por contraste exterior, «lo que no hay» en ella. En este sentido la teoría literaria, a partir de propuestas como la de Lore Terracini (1988), alcanza a vislumbrar los códigos de silencio, a la vez que llega a contrastar el silencio de los códigos. El primero se puede definir como «el conjunto de signos que se introducen en un texto para expresar en forma indirecta un contenido determinado que se silencia» (Bobes, 1992: 105). El silencio de los códigos aparece cuando se descubre «que las formas de expresión utilizadas en una época, por un artista, son incapaces de expresar, comunicar o establecer el diálogo y obligan a determinados interlocutores a callarse, a guardar silencio» (105). Tómese como ejemplo los casos de Racine, Juan Rulfo y Pérez de Ayala. 


\section{El silencio del subtexto}

Este tipo de silencio se sitúa bajo la palabra utilizada como voz. Es decir, es un silencio que llega al lector - es él quien lo percibe-en el subtexto a través de un exceso verbal del texto. En este sentido, cuando en el discurso literario la palabra sólo se reduce a voz nos encontramos frente al más denso de los silencios, porque en estos casos la voz es palabra sin palabra, la palabra se usa para nada, o mejor, para reclamar el silencio. Ejemplo de este silencio son aquellos personajes silenciados más no silenciosos, que no callan y no dicen nada como la Sra. Smith en la primera escena de La cantante calva, de Ionesco (1950) o Carmen Sotillo que habla cinco horas seguidas con el cadáver de su marido en la novela del español Miguel Delibes Cinco horas con Mario, nunca, dice Bobes Naves, «antes del teatro del Absurdo, se había utilizado la palabra para evocar tan intensamente el silencio» (Bobes, 1992: 108).

\section{Formas del silencio literario}

\section{El silencio como tema (hablar del silencio). Su retórica}

Aquí se habla del silencio en oposición a todos los demás temas posibles en la obra literaria (silencio de Dios, silencio de los temas que no encuentran expresión, silencio de los hombres que prefieren callarse, entre otros). Bobes Naves presenta algunos casos en los que, a la par que se ilustra el tema del silencio, el autor «lucha contra una palabra insuficiente que retóricamente exige elipsis, oxiomorones [sic] continuados, movimiento tonal hirsuto de puntos, comas, interrogaciones, monosílabos urgentes, recurrencias, etc., aparte de un tratamiento de los campos semánticos y del léxico [...]» (Bobes, 1992: 112). De tal forma que en un mismo texto diversas formas de expresión se superponen con frecuencia, lo que no permite encontrar los tipos puros de silencios antes enunciados, es decir, la retórica del silencio da lugar a expresiones diversas en cada texto.

\section{El silencio de los códigos}

Si el hombre supiera con claridad todo lo que quiere decir, y pudiera comunicarlo con un sistema unívoco y suficiente, no podría hablarse de silencios. Bajo estas circunstancias se debe de reconocer pragmáticamente el silencio y de esta manera poder buscar sus causas más allá, en ocasiones de la voluntad de los hablantes, y de sus silencios intencionales.

En gran medida, los silencios son hechos del sistema semiósico (referentes performados) y sólo se presentan parcialmente en otros procesos sémicos (expresión, signifi- 
cación, interpretación). Cuando los silencios proceden del mismo sistema sémico, nos encontramos en el territorio de lo inefable, frente a aquello que no puede ser dicho o explicitado, es decir, lo que queda fuera de la palabra, pero que es intuido por el hombre.

Para Bobes Naves es difícil encontrar plasmado en un texto un tipo puro de silencio, en esta medida

Lo inefable, como valor fuera de la palabra, se confunde, o se solapa, al menos con el sentimiento de que la palabra es insuficiente y el autor lucha por ella para dar forma, hasta donde alcanza, a los propios mensajes, pero también se solapa con el sentimiento de que la renuncia a la palabra es una conducta voluntaria y se realiza, por tanto, con el sujeto del proceso semiósico, si bien las razones de esa renuncia se encontrarían en una característica de la lengua: su insuficiencia. (Bobes, 1992: 117).

Como ejemplos de esta conducta voluntaria habría que situar autores como Racine, Pérez de Ayala y Rulfo, quienes se callaron cuando su palabra era suficiente, rica y adecuada al discurso dramático, al relato, a la expresión lírica.

\section{El silencio esquemático:}

La profesora Bobes Naves, tomando como referente a Claudio Guillén, plantea que «el silencio se hace "estéticamente perceptible" por medio de figuras retóricas de elisión o por contraste del discurso con esquemas formales de tipo gramatical» (Bobes, 1992: 118), es decir, aquellos esquemas de tipo lingüístico o normativos de la forma, como leyes de turnos y la distribución del diálogo o de tipo ideológico.

El caso más extremo, en el que se pueden presentar silencios al fallar una de las condiciones del diálogo, es cuando uno de los sujetos se niega a escuchar e intenta cambiar la conversación hacia otros temas. A su vez, bajo una apariencia de diálogo formal, el oyente puede fallar, cuando desvía el tema por falta de atención. Un tercer caso ejemplificado por la autora, es cuando bajo la apariencia de diálogo se esconde un discurso, en el que uno de los interlocutores argumenta, mientras el otro sólo se limita a asentir de vez en cuando.

\section{Entre nudos y capas: las estructuras del silencio}

En la primera parte del estudio El exilio de la palabra. Del silencio bíblico al silencio de Auschwitz (originalmente publicado en 1970), André Neher elabora, sucesivamente, una morfología, una sintaxis y una semántica del silencio en la Biblia. A pesar de que 
el autor concentra su análisis en el libro sagrado, su propuesta estructural del silencio, enmarcada en el aparte dedicado a la sintaxis, resulta fundamental para nuestro propósito, ya que a partir del uso de dos nociones: nudos y capas, Neher logra determinar el papel que juega el silencio en diferentes libros de la Biblia.

Para André Neher, en la Biblia, las estructuras del silencio se caracterizan porque en su conjunto y no únicamente en algunas de sus partes: el silencio no es exclusivamente un objeto; es, la mayoría de las veces, sujeto. Para el autor, en determinadas ocasiones, «se habla de él como de una cosa, en tercera persona, como se habla del sol, del sueño o de la sabiduría, [pero] mucho más a menudo el silencio interviene en la Biblia en primera persona; desempeña en ella un papel activo y dominante. [...] el silencio es uno de los actores y uno de los actores más decisivos de la vasta aventura bíblica» (Neher, 1997:21).

Para efectos del análisis, el autor hace uso de las nociones de nudo y capa como una forma de determinar y aplicar dos estructuras equitativamente repartidas a lo largo de la Biblia. Como nudos entiende «esas emergencias rápidas y fugitivas de un silencio que aparentemente nada prepara ni prologa» (Neher, 1997:22). Entre los ejemplos suministrados se encuentran: el enigmático silencio de Dios en pleno corazón de una consulta de Jeremías $(42,7)$ y la detención brusca de la frase de David al final del capítulo 17 del Primer Libro de Samuel. Pero a esta categoría debemos añadir toda la «red tejida por los procedimientos internos del lenguaje» (22), es decir, todas las pausas a través de las cuales las palabras respiran, o los intervalos blancos en la disposición de la frase bíblica por los que, subrepticiamente, se introducen silencios cargados de múltiples significados. Los signos gramaticales, en conclusión, «confieren al texto bíblico, por sí solos, una estructura semi-oral, semi-silenciosa. Sobre la escena de la frase bíblica, el silencio surge regularmente, como el actor, de una trampa. Está presente por doquier en la ausencia de la palabra» (22).

En cuanto a la presencia estructural del silencio en la Biblia en forma de capa, Neher plantea «un silencio que se extiende sobre un capítulo entero y, en ocasiones, todo un libro bíblico,[...] tan pronto subterráneo como visible, transformando ese capítulo o ese libro en un lago de silencio, ya se trate del silencio del hombre o del silencio de Dios» (Neher, 1997: 22). Entre los ejemplos destacados se encuentran, la epopeya sin palabras de Génesis 6, 9 a 9, 25, en la que Noé ini siquiera pronuncia una palabra!, la del Libro de Ezequiel «cuya estructura se confunde, casi íntegramente, con una aventura del silencio» (23), y los cuarenta y dos capítulos del Libro de Job sostenido por el silencio por todos sus ángulos. (Neher, 1997: 22). En síntesis, cuando el silencio se presenta en forma de capa en el texto bíblico, se convierte en actor principal. «Es alrededor de él, gracias a él, pese a él, contra él, como todo se deshace y se hace» (23). 


\section{Tres perspectivas del silencio. Silencios del autor, del texto y del lector}

Para el poeta y crítico peruano Eduardo Chirinos la experiencia poética se constituye como una compleja experiencia de silencios, «los silencios que proceden y acompañan los actos de escritura y de lectura, los silencios del autor y del lector, los silencios del hablante y del locutor, los silencios del texto mismo» (1998: 28-29). En resumen, son tres los silencios: del autor, del texto y del lector.

Ahora bien, cabe destacar que ninguna de las tres propuestas recogidas por Chirinos está diseñada en torno a la obra de un poeta particular, antes bien, postulan un alcance general, tanto así que podemos partir de ellas para realizar una posterior adecuación y así aplicarlas a las obras narrativas objeto de nuestro análisis.

\section{La perspectiva del autor}

En primer lugar, Rae Armantrout (1985), haciendo uso de ejemplos extraídos de la más reciente poesía norteamericana, sostiene, entre otras cosas, que «es la voluntad del autor la que decide, mediante el uso de determinadas estrategias, la inclusión de silencios en el poema» (Chirinos, 1998: 32). De tal suerte que al responder la siguiente pregunta: «Suppose a writer wants to make room in her work for silence, for the experience of cessation; how is this accomplished?» (Armantrout, 1985:24), logra presentar seis maneras que regulan y determinan la inclusión del silencio en el poema gracias al omnímodo poder autorial, trascribo la respuesta:

1. She may end a line or a poem abruptly, unexpectedly, somehow short of resolution.

2. She may create extremely tenuous connections between parts of a poem.

3. She may deliberately create the effect of inconsequence.

4. She may make use of self-contradiction or retraction.

5. She may use obvious ellipsis.

6. She may use anything which places the existent in perceptible relation to the non-existent, the absent or outside. (Armantrout, 1985:24).

Sin embargo, si bien estas seis estrategias son pensadas y articuladas por el autor (a), solo llegan al lector de forma virtual en un texto que multiplica la pluralidad de significados, al tiempo que ofrece indicaciones de cómo debe ser leído. Es decir, la intencionalidad del autor se hace relevante, siempre y cuando sea él mismo - mediante el proceso de escritura- quien nos acerque al «contexto de sus intenciones» y no 
pretenda por el contrario erigirse como dueño absoluto y autoritario del significado de sus poemas. De todas formas - advierte Chirinos-:

La presencia de estos silencios y desajustes en el poema no constituye pautas elaboradas por el autor y dejadas en el texto como «pistas» para que el lector descodifique correctamente la clave secreta de sus intenciones. Muy por el contrario, a pesar de presentarse como una «confesión autorial» (es decir, como poética y como biográfica), el hablante indetermina el discurso, lo abre, y al hacerlo despoja al autor de cualquier intento de controlar el sentido (Chirinos, 1998: 39).

En su estudio Una retórica del silencio (1994), Lisa Block de Behar sienta las bases de una retórica que no debe ser entendida como elocuencia o como un catálogo de preceptos y curiosidades, sino como una teoría del discurso, en la que el autor aparece unido, gracias al silencio, a un participante activo (lector) a través de ese «objeto silencioso» en que se constituye la obra literaria. El silencio - para Block de Behar- «es la condición necesaria para interpretar los silencios de la lectura, para buscar el significado de lo no dicho» (Chirinos, 1998: 40).

\section{La perspectiva del texto}

En su ensayo «La retórica del silencio» Amparo Amorós trata de dar respuesta a la pregunta «¿Qué recursos expresivos genera el silencio para hacerse oír en un texto?». El resultado no podría ser mejor: una meditada reflexión sobre los riesgos de la retórica del silencio en la tradición poética española. Algunos de los puntos destacados por Amorós en su ensayo, se transcriben a continuación in extenso:

a. Supresión de todo elemento considerado retórico «en el sentido peyorativo del término», en busca de la desnudez expresiva, la concentración y la sobriedad.

b. Eliminación de nexos innecesarios, «brindar la sintaxis, entrechocar-mediante asociaciones insólitas, sorprendentes, imprevistas - las palabras como piedras para que estallen, hacerlas restallar contra su propia opacidad como látigos y apuntar al blanco semántico como arcos tensados por procedimientos lingüísticos».

c. Uso de técnicas cinematográficas «para reflejar ciertas zonas de la realidad escondidas o relevantes, provocadoras o insignificantes, o ciertos trazos fugaces que han traducido una visión entrecortada y fustigante como la respiración de la angustia».

d. Utilización «del espacio tipográfico de la página para escribir en él breves y sintéticos poemas que recuerdan la tradición de los Hai-ku o las Greguerías». 
e. Fragmentarismo, comienzos «in media res» y finales bruscos, «como chispas brotadas, del pedernal, luces instantáneas en medio de la noche. Y ese vacío operado en torno al texto y su propio carácter sugerente y enigmático ha funcionado como un auténtico vacío físico absorbiendo al lector, devorándolo, incluyéndolo en el poema hasta hacerlo participar en él como co-autor».

f. «Intento de ensordecer el poema, de quitarle musicalidad, pensando que era excesiva y superficial».

Las estrategias antes expuestas cumplen una función higiénica contra los excesos ornamentales (verbales), pero paradójicamente el uso excesivo e indiscriminado de estas mismas estrategias trae consigo el riesgo de propiciar una nueva retórica, a decir, en términos de Amorós, una retórica del silencio.

Por otro lado, Ramón Pérez Parejo en «Qué es silencio y qué no es silencio. Claves de una poética» (2013), se detiene a describir la retórica del silencio, es decir, las claves estilísticas de esta tendencia poética. Para ello elabora de forma didáctica un decálogo de factores o componentes de tal estética intentando señalar sus claves estilísticas:

a. Criterios generales: que rigen la poesía del silencio son la estética de la economía y la estética de la selección.

b. La tipografía y versificación: inclinación o un predominio de los poemas cortos, la versificación corta, la ausencia de rima y la participación significativa de los espacios en blanco.

c. La sintaxis: La sintaxis apunta también a la brevedad y a la selección. Lo que más caracteriza al poema es la ruptura de la sintaxis lógica, por lo que queda en suspenso el sentido.

d. Las figuras estilísticas: los recursos estilísticos van encaminados a potenciar ese doble efecto de brevedad y densidad, entre las figuras más destacadas se encuentran: sutiles connotaciones, insólitas asociaciones, frecuentísimas contradicciones y paradojas llenas de contrasentidos significativos que el lector debe completar o interpretar, alegorías, invocaciones y apóstrofes, continuas elipsis, zeugmas, ironías, suspensión, reticencia. Paréntesis, lítotes, tendencia al hermetismo.

e. El plano léxico-semántico: se destaca el afán de selección y abstracción, los sustantivos, escasez de adjetivos, parquedad de verbos (predominio de la reflexión sobre la acción).

f. Las coordenadas espaciales: tendencia a lo sustantivo, es frecuente la descripción, pero se hace escuetamente, trazando unas breves pinceladas impresionistas o abstractas.

g. Las coordenadas temporales: se caracteriza por el «anacronismo», por la completa anulación del tiempo, que parece detenido. Desaparecen los deícticos de tiempo y espacio, o bien se difuminan en lo inconcreto. 
h. La focalización lírica: se destaca la ocultación o escamoteo del sujeto. La figura del sujeto lírico tiende a desaparecer, a difuminarse entre el blanco de la página. Renuncia del yo mediante técnicas de diseminación, de dialogismo, de otredad, entre otros.

i. El cromatismo y la decoración: El color dominante es el blanco, traslación metafórico-cromática del silencio y de la página en blanco.

j. Los tópicos asociados: la noche, las escalas, las galerías y penumbras indescifrables, la altura, lo celeste, las fugas, la luz que guía, las azucenas, etcétera. Otros símbolos se repiten insistentemente como el sueño, el espejo o la nieve, figura de uso y tópico metafórico del blanco (de la página), de la ausencia, del silencio.

\section{Del sentido problemático del idioma}

El culto consciente y sistemático del silencio - bien lo señala Alan S. Trueblood- se nos muestra como preocupación relativamente moderna (1958:162). Desde el Romanticismo a la actualidad, el silencio ha sido explotado como elemento estético en forma más sistemática que antes. Esto sucede porque «la imposibilidad de decir ha sido paradójicamente el motor de toda necesidad de expresión artística» (Acosta, 2006: 6); pero es precisamente el hombre romántico y específicamente el romántico alemán el precursor - podríamos llamarlo- de una nueva sensibilidad, que ante todo buscaba expresar lo inexpresable, lo inefable, lo inabarcable.

De tal forma que la historia moderna va en contravía de la tradición en la que el lenguaje se funda en una verdad superior. De aquí en adelante hace carrera cierto escepticismo ante el lenguaje: Rimbaud realiza una «invitación al silencio», mientras llega «el tiempo de un lenguaje universal»; Mallarmé postula una escritura del silencio, de purificación, para dar un «sentido más puro a las palabras de la tribu»; entretanto, Nietzsche diagnóstica la crisis y el desprestigio del lenguaje que más adelante Sontag terminará por confirmar:

Como el hombre ha creído, durante largos espacios de tiempo, en las ideas y en los nombres de las cosas como en aeternae veritates, es por lo que se creó ese orgullo con el cual se elevaba por encima de la bestia: creía realmente tener en el lenguaje el conocimiento del mundo. [...] Fue mucho después, en nuestros días tan sólo, cuando los hombres comienzan a entrever que han propagado un error monstruoso en su creencia en el lenguaje. (Nietzsche, 1984: 47).

A partir del Modernismo en la literatura en lengua española se logran evidenciar vestigios de un uso más consciente del silencio como elemento expresivo. Un ejemplo es rescatado por Trueblood a propósito de la obra de Amado Nervo: 
[...] El silencio, anticipo de la paz del nirvana, representa la suprema sabiduría. «Voy hacia el silencio», escribió Nervo a Alfonso Reyes en frase que demuestra el peligro de una preocupación demasiado insistente por el silencio, por lo inexpresado, en la creación literaria. Cuando llega a dominar, el silencio acabará sencillamente por matar el arte. Aun cuando su papel es auxiliar, es evidente que se requiere un talento nada común para lograr un personaje dramático o novelístico que no habla, o para comunicar un estado lírico que se esboza apenas. [El subrayado es mío] (Trueblood, 1958: 161).

Salvo la última parte, concuerdo con el autor. Si bien es evidente que se requiere de un talento excepcional, nada común, para escribir y de paso manifestar una conciencia plena del silencio en la obra literaria (de hecho Trueblood trata de corroborarlo en Cervantes a partir del análisis del Quijote), parte de mi hipótesis consiste precisamente en demostrar que el silencio, si bien ha sido subestimado, para nada cumple un papel auxiliar, en el proceso de la comunicación en general y en la obra literaria en particular.

Concentremos ahora nuestra atención en algunas propuestas que plantean el silencio como acto mismo de la escritura. Susan Sontag en su ensayo «La estética del silencio» nos advierte de la situación desdichada en la que se encuentran las artes en la contemporaneidad, producto de la naturaleza dual del lenguaje - su condición abstracta y su «degradación en la historia»-. En tal sentido, «[...] el lenguaje es el más impuro, el más contaminado, el más agotado de todos los materiales que componen el arte» (1985: 23). Ante esto se hace visible una búsqueda del silencio, un «apogeo de la resistencia a comunicar» del que habla Sontag, una constante en la que se focaliza el arte contemporáneo con el objeto de explorar sus propios límites.

Ejemplo son algunos autores contemporáneos que han postulado el silencio como experiencia purificadora del lenguaje, de la palabra, en contravía a «[...] una civilización en la que la inflación constante de la moneda verbal ha devaluado de tal modo lo que antes fuera un acto numinoso de comunicación en que lo válido y lo verdaderamente nuevo ya no pueden hacerse oír» (Steiner, 2003: 71). Las ficciones de Samuel Beckett y William Seward Burroughs dan muestra de esta búsqueda por apabullar el lenguaje, a fuerza de mucho hablar; pero de un hablar que es tanto palabra como silencio. «Porque la exhortación contemporánea al silencio nunca ha reflejado exclusivamente un rechazo hostil del lenguaje. También implica un gran respeto por el lenguaje: por sus poderes, su salud pasada y los peligros que encierra actualmente para la conciencia libre» (Sontag, 1985:36).

Es, entonces, nuestro interés la construcción de una poética que, como lo plantea J. A. Valente en Cinco fragmentos para Antoni Tàpies (1979), "es arte de la composición del silencio". Arte de la composición que manifiesta atracción por un material silencioso. Sin embargo, antes de seguir adelante conviene precisar que aun cuando con frecuencia se ha pensado que es el poeta quien debe librar un combate con el lenguaje, de esto dan 
cuenta un sinnúmero de trabajos ${ }^{7}$, la condición de narrador no se encuentra exenta ni excusada de dichos problemas. De hecho, autores como Felisberto Hernández (Uruguay), Efrén Hernández (México) y Francisco Tario (México), entre otros, escriben un silencio que acaba convirtiéndose en núcleo temático y espacio por excelencia para la práctica de la metaliteratura y de la autoconciencia.

\section{La metáfora del silencio}

En el capítulo «La metáfora del silencio» de la obra La máscara la transparencia (1985), el crítico y poeta venezolano Guillermo Sucre lleva a cabo un repaso por diferentes autores hispanoamericanos en los que se encuentran diversas variantes de la experiencia del silencio: Gonzalo Rojas (Chile), Cintio Vitier (Cuba), Alberto Girri (Argentina), Juan Sánchez Peláez (Venezuela), Rafael Cadenas (Venezuela), Reynaldo Pérez-Só (Venezuela), Eugenio Montejo (Venezuela), Homero Aridjis (México) y Alejandra Pizarnik (Argentina). En su ensayo, Sucre presenta el silencio como una doble metáfora. Por un lado, como experiencia purificadora (del lenguaje, de la palabra), que no sólo es leída en el orden estético. Por otro, como exigencia de totalidad que se vuelve sobre sí misma y se hace crítica. A su vez, esta doble metáfora implica para Sucre:

\footnotetext{
(...) la nostalgia de la Palabra, es decir, la búsqueda de un lenguaje ya tan absoluto (¿sagrado?) que puede identificarse con el silencio mismo. Esa nostalgia aviva a su vez, y aun la expone al abismo, la conciencia de otra verdad: se escribe con palabras que son la traducción (la pobre traducción temporal, subraya Borges) de la Palabra. De un modo u otro, esta es la conciencia del poeta contemporáneo. (1985:294).
}

Conciencia que bien es rastreada por Guillermo Sucre en estas nueve voces reveladoras de la poesía y cuya experiencia del silencio revela una serie de elementos fundamentales para nuestro análisis. En primer lugar, Gonzalo Rojas logra introducir una connotación metafísica en torno a la metáfora del silencio. En su obra poética el silencio se presenta como la verdadera palabra, como la «voz única», como la morada del ser, la realidad y la no-realidad del mundo. La obra del chileno se destaca por su elocuencia, producto de una retórica envolvente. Su poesía posee una intensidad eró-

\footnotetext{
7. A propósito, Eduardo Chirinos dice que «la poesía ha sido siempre un espacio privilegiado para poner en escena las discusiones sobre el tema del silencio. La secular fascinación de los poetas por el silencio en sus múltiples manifestaciones (poder y censura, revelación y conocimiento, suspensión y espera, esterilidad y creación) se radicaliza en la modernidad y se traduce en la capacidad del poema de ser leído como representante dramático del acto mismo de la escritura» (1998: 230).
} 
tica que exige la exuberancia y la carnosidad verbal, características que contrastan con versos breves, austeros e incisivos.

Una metáfora del silencio más persistente se encuentra en la obra del cubano Cintio Vitier, en el sentido de una relación extrema con la creación poética: «El silencio no es un dilema; más bien hay que verlo como rigor, disciplina, ascesis» (Sucre, 1985: 296). La poesía - similar a lo propuesto por Rojas - revela el carácter silencioso de la verdadera palabra. En este sentido, el silencio cumple una doble función: separa al poeta de la palabra como habla a la vez que lo enfrenta con ella. De allí que el silencio no exija callarse, por el contrario, es el camino que conduce al poeta al reencuentro con la palabra. Vitier plantea un debate con el lenguaje en el que el silencio se expresa a sí mismo. De tal forma que busca un lenguaje elemental, una experiencia purificadora de la palabra tan crucificada por la escritura: «[...] una precisión tal que colinda con una mística del lenguaje en la que este se vuelve verdadera escritura, icónica, sagrada» (298). Para conseguirlo, a través de un evidente dominio verbal, Vitier opta por un lenguaje extremadamente austero, despojado y sencillo.

Alberto Girri, entre tanto, hace su crítica del lenguaje sabiendo que lo está haciendo dentro y no fuera del mismo. El poeta argentino, al igual que Rojas y Vitier, concentra su atención en la tensión-sinergia que se da entre la palabra y el silencio, en la medida en que no desconoce al poema como objeto verbal: la verdad del poema - dice- «no reside sino en su propia escritura». Sin embargo, pocos como él tienen tanta conciencia de «lo banal y absoluto de la escritura». De esto, tal vez, se desprende su descreimiento hacia la exuberancia y prodigalidad de todo lenguaje y más bien prefiera un extremado y abrupto despojamiento del instrumento poético. En definitiva, si Girri «[...] vive en el reino de la palabra [...] es para mostrar su exilio: la palabra está ausente del mundo, o mejor, el mundo la ha vuelto una ausencia» (Sucre, 1985:300).

En Juan Sánchez Peláez la metáfora del silencio admite otras connotaciones, al punto que parece el resultado de un «pensamiento que sabe callar al hablar» (Sucre, 1985: 303). Su obra poética tiende en principio a la exuberancia y aun al desencadenamiento verbal, pero paulatinamente se va despojando de cualquier exceso, en cuanto «la palabra accede a una simplicidad tal que ello mismo parece la transgresión de "lo poético"» (302). Este despojamiento o rechazo de toda proliferación verbal supone la confrontación directa con el lenguaje de una obra que se caracteriza por poemas breves, o de versos muy cortos imprevisiblemente espaciados en la página, rodeados de mucho blanco. La poesía de Sánchez, como dice Sucre, «no ha dejado de ser "oscura" en ambos aspectos: no solo se salta todos los nexos explicativos y le gusta ser elíptica; también exige que la imaginación del lector siga el proceso del poema, y no se quede únicamente en su sentido» (302).

Rafael Cadenas comparte similitudes con Sánchez Peláez a la hora de establecer una confrontación con el lenguaje. Su obra poética tiende inicialmente a la exuberan- 
cia, a un deslumbramiento ante los poderes no sólo verbales, sino de la imaginación; luego se despoja de cualquier exceso verbal; pero ya no es mero despojamiento, sino «el despeje que abre la verdadera "ruta" hacia lo real» (Sucre, 1985: 304), hacia una relación directa con el mundo, en la que la palabra sirva a esa relación. Entonces el silencio se opone al verbalismo, ya que «la nitidez empieza por el propio lenguaje, por ese "lenguaje de fondo" que renuncia a todo extravío esotérico y se niega a cualquier mixtificación verbalista» (305).

El silencio no es mero callarse, lo que se calla es todo proceso mental especulativo que interfiera entre la palabra y su plena relación con el mundo, de allí que entre las características de su obra se encuentren la extrema economía verbal y el laconismo. En definitiva, en Rafael Cadenas encontramos la verdadera pasión del lenguaje y del silencio. Encontramos no el callarse, sino la palabra silenciosa.

Aunque la obra de Reynaldo Pérez-Só no parece plantearse dilema alguno ante el lenguaje como tal, sí presenta una coincidencia entre la palabra y el silencio: la mesura. Pérez-Só parece no entregarse a los incontables espejos y espejismos de la palabra, por eso tal vez excluya de sus recursos todo aquello que pueda relacionarse con grandes metáforas, ideas o emociones. Nada en su obra se nos da explícitamente. «Lo que aparece es solo el poema, el texto: un objeto verbal muy breve, luminoso pero no destellante, indeterminado pero no impreciso, instantáneo pero también simultáneo» (Sucre, 1985: 308). Si algo caracteriza la obra poética de Pérez-Só es su fragilidad textual, su obra admite Sucre - nos convoca a cierta inocencia del lenguaje y de la vida.

Eugenio Montejo tampoco parece plantearse dilema alguno ante el lenguaje y la mesura es, como en la obra de Pérez-Só, el elemento coincidente entre la palabra y el silencio. Pero a diferencia de su compatriota, su labor poética se ha caracterizado por el espesor y la rica gama textual, por un sentido exigente de las formas verbales, al punto que una suerte de hilado verbal se ha constituido como uno de sus signos identitarios. Uno de los más profundos debates de su obra es saber «a un tiempo que la poesía es "forma" y que ésta ya no expresa lo sagrado» (Sucre, 1985:310). El mismo uso del vocablo fabla hace latente el gusto por un lenguaje arcaico y fabulador. Sin embargo, Montejo no logra caer en lo divagatorio y deshilvanado, no describe, ni enumera y tampoco se deja llevar por una fabulación genésica. Por el contrario, en «toda su obra es muy evidente la entonación mesurada, la trama reflexiva y aun irónica que la aleja de cualquier desencadenamiento visionario o verbal» (312). No cabe duda de que en Montejo se hace latente con igual intensidad una fascinación por el lenguaje y el silencio. La palabra es el deber ser del poeta, pero este debe - como advierte Sucre- saber callar para impregnarse de mundo, para que sea este el que escriba sus propios signos.

Otra variante de la metáfora del silencio está presente en la poesía de Homero Aridjis. En su obra parece que «el silencio habla con plenitud [y] el lenguaje calla con precisión», ya que todo lo que allí está presente parece signo del silencio: la concisión, 
la música exacta, el trazo puro, dejando a un lado los giros oblicuos o sorprendentes, o las tramas verbales demasiado densas, todo esto en busca de una claridad, de la verdadera transparencia que le dé a la poesía «una nitidez verbal que es igual al silencio: la palabra que ni revela ni oculta» (Sucre, 1985:316). La relación que se establece entre palabra y silencio es central en Aridjis, su poesía denota amor por los nombres, pero también por el silencio. En su obra la palabra es portadora del mundo, pero esta «sopla desde el fondo del agua silenciosa», porque «el silencio está al comienzo y también al final de la palabra» (312).

Alejandra Pizarnik, por su parte, logra transponer la metáfora del silencio al plano mismo de su vida. El suicidio se constituye como la última manifestación de esa metáfora; pero - aclara Sucre-manifestación no equivale a realización. Para Pizarnik la muerte se presenta como metáfora del lenguaje (¿del fracaso del lenguaje?) y cuando este es acompañado por el silencio se constituye la metáfora total. De tal suerte que su poesía se funda en una continua meditación sobre el acto poético mismo, en la cual se transpone la vida a la escritura y la escritura a la vida, de allí que «no tener nada que decir supone que no hay tampoco nada que vivir» (Sucre, 1985:317). El artista va en busca de la transparencia, a un lugar de fusión y de encuentro con el lenguaje, por eso «escoge la muerte por amor a la vida, escoge el definitivo silencio por amor a la palabra» (318).

\section{Entre el silencio sintagmático y el silencio primordial... originario...}

En su texto «Prólogo al silencio» Marcè Rius se propone, frente a la actitud tradicional acerca del lenguaje y sus relaciones, mostrar cómo la inmanencia o trascendencia del silencio son dos caras de una misma moneda. En tal sentido nos dice:

\footnotetext{
[...] Ambos - trascendental y empiria - están indisolublemente unidos. El habla es no sólo la plasmación de cuantas perfecciones anidan en el lenguaje (Silencio = lo Mismo), sino también el punto donde se resuelven o disuelven sus problemas (Silencio = lo Otro). Tanto si hemos de callar por imposibilidad «lógica», como si debemos hablar, ya para realizar, ya para producir el lenguaje, se establece entre ambos polos una comunicación proclive a ahuyentar las interferencias. (Rius, 1984: 136).
}

Desde esta perspectiva son dos los silencios propuestos: un silencio denominado sintagmático, el cual no debe ser considerado como un dato último, y otro silencio, primordial, originario, que actúa como condición de posibilidad de todas sus manifestaciones empíricas. En primera instancia Marcè Rius parece oponerse - en todo o en parte- a la concepción tradicional que reconoce al silencio como una pausa cuyo 
valor es de dependencia sígnica, es decir, el silencio es mera apoyatura del significado, recibiendo así «el privilegio de servir a un amo más ilustre» (Rius, 1984: 133).

Bajo la denominación de silencio sintagmático, Rius recoge una tipología de silencio que desempeña un papel importante en la transición del paradigma al sintagma lingüístico, en tanto el paradigma es tan sólo un «sistema de signos, meramente estructural... poco dialéctico», y necesita del acontecer de la articulación sintagmática, ya que de ella adviene un sentido que no poseen los signos por sí mismos. Solo en la ejecución del denominado paradigma - en el habla- emerge el sentido (se debe reconocer que con la realización verbal, emerge algo nuevo) y es en la realización efectiva de esta habla en que se registra el aporte sustancial de un silencio que actúa con entidad propia, ya que no pertenece al paradigma.

Recostadas sobre el silencio las palabras adquieren relieve. El habla adquiere espíritu, energía, vida, poder de generación y el lenguaje se convierte en la verdadera esencia que el habla realiza en el discurso. Sin embargo, para la concepción dialéctica, el silencio no existe fuera del logos, porque es solo «un momento de la finitización del lenguaje, y este acaba por recuperarlo en el seno de su absolutez» (Rius, 1984: 134). Es cierto que bajo esta perspectiva la condición finita del silencio se hace latente y que está condenado-como dice Rius-a aniquilarse en el reino del sentido; pero tampoco cabe duda de que la mencionada racionalidad no invalida los derechos antes restituidos. El silencio - digámoslo-es más que una pausa retórica, es más que una unidad que confiere sentido a las palabras, ya que las enriquece, porque el silencio las habita como horizonte de potencialidades actualizables.

El silencio originario, por su parte, está preñado de sentido, en él germina el discurso; pero parece contradictorio que cada acto discursivo, en tanto efectuación limitada, reduzca las posibilidades iniciales contenidas en el silencio originario. Algo similar propone Kovadloff cuando nos dice que el poeta debe «proyectar en las palabras la insinuación de una presencia inabarcable». Entonces, mientras el silencio sintagmático no posee una existencia propia, ya que es inherente al habla, al logos, que va unido a ellos de un modo inseparable a su esencia, aunque racionalmente podemos distinguirlo; el silencio originario trasciende el plano de la mera articulación del sentido sintagmático, impidiéndonos afirmar «que el verdadero ser del silencio es el lenguaje» (Rius, 1984:134), ya que «hemos de sustentar que el silencio es lenguaje, o no es» ${ }^{8}(134)$.

8. En su trabajo, Max Colodro parece presentar al silencio como uno de los elementos fundamentales del lenguaje, a pesar de que no es parte suya. El silencio al que apunta este conjunto de ensayos - dice en la Introducción- «es precisamente [...] aquel conformado por una cualidad que podría hacerlo significante por símismo, aunque no deje de permanecer en el orden mudo de lo innombrable, de lo indecible e inexpresable» [El subrayado es del autor] (2004: 11). 
Si el silencio es el origen del lenguaje, incurrimos en una contradicción que nos arroja nuevamente a su condición finita, aquella que niega categóricamente su entidad separada del habla. No podemos, desde esta perspectiva, eludir la inmanencia, que nos obliga a decir el silencio desde el lenguaje ¿por qué? Porque sólo podemos representarnos en él. Con el objeto de resolver esta contradicción y de paso no renunciar al abordaje de la problemática del silencio desde otras ópticas, se ha propuesto - desde la misma filosofía- desentrañar el asunto a partir de la oposición ausencia-presencia, como una vía de escape a la tradicional ser-no ser, huyendo de esta manera de la metafísica. En todo caso este abordaje desde la ausencia-presencia, parece responder a la ya vieja repulsión filosófica por la trascendencia. Bajo esta perspectiva el silencio no existe «en tanto presencia originaria que desvela su verdad en el acto del habla, sino como huella producida por la escritura» (Rius, 1984: 135). Parece que el resultado no puede ser otro: el silencio sigue sometido al sentido y esta negativa a reconocer su carácter trascendente, es sólo un exorcismo contra el fantasma de la irracionalidad.

La filosofía y la misma crítica literaria se niegan a teorizar sobre esa trascendencia del silencio. Un grupo - dice Rius-, acotando el terreno filosófico, trata de poner límites al sin sentido; estos pensadores son los que deciden detenerse en la tradición y privilegian al significado por encima de la expresión. Por eso - enfatiza la autora-su silencio consiste en callarse. Pero entre estas posiciones sesgadas, reduccionistas del sentido mismo, emerge el silencio primordial, originario, como contraposición. Es la propuesta de aquellos que desean expresar ese silencio no poniéndole límite. De tal suerte que «el silencio originario solo es peligroso porque suele reaparecer como punto y final del camino» (Rius, 1984: 135) [El subrayado es mío].

\section{El silencio primordial}

«El silencio - advierte Sucre - está al comienzo y también al final de la palabra» (1985: 312). En un sentido complementario, Santiago Kovadloff anuncia a una «palabra en el abismo». ¿Cuál abismo? El silencio mismo. Pero no el abismo derivado del superlativo de uso vulgar abisimus (abyssimus): muy profundo. Sino de aquel que viene del griego

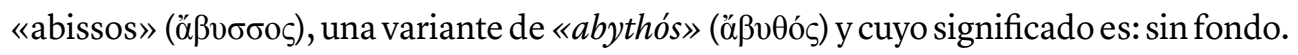
Existe una gran diferencia entre una palabra que emerge de lo muy profundo y aquella que lo hace de una fuente sin fondo.

Para Kovadloff (1993) el silencio humano no sólo expresa mediante la prescindencia de las palabras. Es más que abstención, privación o acallamiento. El silencio es más que la contracara de la expresión. De tal suerte que en el primer capítulo de su libro $E l$ silencio primordial, nos acerca a la naturaleza dual del silencio, a su naturaleza abismal. El silencio es principio y fin... leemos palabras que parten y retornan a él. Para Kovadloff 
este principio y fin de la palabra se corresponde con dos dimensiones del silencio. El silencio oclusivo, del que parte el poema y el silencio epifánico al que arriba y desemboca. Es decir, el poema va de silencio a silencio, su tránsito recorre lo abismal, lo que aún con palabras no se logra del todo enunciar.

El silencio oclusivo es fruto de una trama verbal, de un lenguaje. Es lenguaje porque «constituye un recorte interpretativo en el campo total de lo inteligible», es decir, «puede nombrar algo de cierto modo, solo a condición de que acalle algo también de cierto modo». Es silencio porque precede al poema, silencio de aquello que ha sido forzado a replegarse, de lo enmudecido, de la palabra encubierta y denegada, de la enunciación posible pero eludida por diversas causas (miedo, hábito, prejuicio).

El silencio epifánico, por su parte, es fruto de la palabra plena. No es un lenguaje, porque no constituye un recorte en el campo de lo inteligible, en él nada se encuentra acallado, con él nada en particular quiere decirse. Mientras en su contraparte oclusiva se puede nombrar a condición de acallamiento, el silencio de la epifanía es inviable para el habla como objeto de aprehensión directa, pues su naturaleza es circundante. Es el silencio de la significación excedida: su sentido - como en la propuesta de Max Colodro- rebasa el significado, de ahí que su poder radique en que puede significar mucho más de lo que pueda ser dicho o apalabrado alguna vez. Sin embargo, la poesía, tan cercana a las palabras es su forma más apta, su manifestación más pura.

Pero lejos de pertenecer a universos contradictorios se buscan, se trenzan y aun se complementan en el poema que va de un silencio a otro. De ahí que «Yendo y viniendo del silencio de la oclusión al de la epifanía, la existencia pareciera insinuar que no entronca por entero ni en uno ni en otro, sino siempre y alternativamente en ambos» (Kovadloff, 1993:31). Pareciera que no todos podemos transitar entre silencio y silencio, que no todos podemos lanzarnos por esa palabra que se encuentra en el abismo, que no todos podemos escuchar el «silencio primordial».

El silencio primordial va asociado a la inspiración. ¿Pero qué es la inspiración? Sin caer de plano en las nociones románticas de «genio» o «inspiración», es una voz que llega de afuera y que habla al oído del poeta cosas que se resisten al entendimiento bajo el nombre de lo indesignable. Es un impacto que disloca al hombre-poeta que lo protagoniza, al tiempo que quien es dislocado se vuelve a situar, pero esta vez en tierra incógnita. En el territorio que domina la página. En la forma escrita. La inspiración crea, extrae de la nada, pero la nada lejos de ser ausencia o vacío, es radical alteridad. La inspiración nunca es un discurso conformado de antemano, ni un mensaje explícito, de tal forma que «no dicta sino que quebranta un dictado. Obstruye, interrumpe, sobresalta y disloca el discurrir de la acepción convencional, del significado impuesto» (Kovadloff, 1993: 29).

¿Quién es el poeta? El poeta es aquel que ha sido inspirado. Es quien advierte el murmullo y le asigna un valor a ese inasible murmullo del habla trascendente. El artista- 
el poeta, en términos de Croce, es quien vive la impresión y luego hace la expresión. Es quien advierte que algo ha venido a decir, mas no qué ha venido a decir. Algo similar propone Collingwood cuando describe al artista como un ser «estimulado por una excitación emotiva cuya naturaleza y origen él mismo desconoce hasta que logra dar con alguna forma de expresarla, la cual implica ponerla en presencia de su mente consciente» (Beuchot y Arenas-Dolz, 2008: 218).

El efecto de esa presencia finalmente se dejará sentir en esa tierra incógnita que antes hemos llamado página, en la que el poeta da prueba de su idoneidad mediante la escritura, pero sin repetir lo que ha escuchado, sino traduciéndolo, porque «la elocuencia sólo puede desplegarse si se nutre donde no impera el entendimiento generalizado de las cosas» (Kovadloff, 1993). En definitiva, el poeta no es «quien sabe instrumentar el idioma, sino aquel que se muestra apto para desembarazarse» (28) de su uso corriente. Entonces, el silencio primordial ilumina el poema, se deja oír entre las palabras inspiradas cuando el poeta ha aprendido a atribuirle un sentido a lo que de por sí no se le puede otorgar.

\section{A manera de conclusión}

Llegar a estos párrafos finales no implica «cerrar» el trabajo estableciendo una síntesis de manera definitiva y concluyente, puesto que no existe una verdad incuestionable, una última respuesta al tema del silencio, ni en la poesía ni en la narrativa. Aún queda mucho por decir. Por el contrario, se espera que las interrogantes planteadas sumen nuevos argumentos y abran nuevas posibilidades de análisis, siempre en la dirección de proponer posibles respuestas que nunca podrían ser categóricas ni mucho menos estables. No obstante, de este recorrido se deben extraer ciertas conclusiones.

Se debe ser consciente de que el camino emprendido es largo, seguramente tortuoso y la construcción lenta; entonces solo queda ponderar los pequeños pasos que hasta ahora se han dado y declarar que sigue siendo objetivo fundamental la construcción de una poética del silencio para la narrativa (o al menos que no la excluya). Poética que es arte de la composición del silencio y que se manifiesta a partir de la atracción por un material silencioso, en la medida que se siente tanto la imposibilidad del lenguaje como el fracaso de la palabra para descifrar una realidad inefable, porque las palabras han perdido su valor y paulatinamente se ha desplazado su poder.

En todo caso la poética del silencio va más allá de una postura ante el lenguaje que se manifiesta - por necesidades expresivas del autor- en la escritura de algunos recursos retóricos o gramaticales (es en este punto en donde se percibe con mayor fuerza la unificación entre retórica, poética y estética). Dicha poética es la fuente misma de la que mana la escritura, es un acto consciente, una necesidad de escribir aquello que no 
se puede decir. Menos aún se resuelve «hablando del silencio» porque una obra literaria que habla acerca del silencio no asegura su inscripción a la estética del silencio: el silencio es una estética resuelta en una retórica, no un tema literario.

\section{Referencias}

ACOSTA LÓPEZ, M. R. (2006). Silencioy arte en el Romanticismo alemán. Bogotá: Universidad Nacional de Colombia. Facultad de Artes.

AMORÓS MOLTÓ, A. (1982). «La retórica del silencio». En: Los cuadernos del Norte III(16). Armantrout, R. (1985). «Poetic silence». Ed. Bob Perelman. En: Writing/Talks. Carbondale: Southern Illinois University Press. pp. 21-47.

BEUCHOT, M. y Arenas-Dolz, F. (2008). Hermenéutica de la encrucijada: Analogía, retórica y filosofía. Barcelona: Anthropos Editorial.

BLOCK DE BEHAR, L. (1984). Una retórica del silencio, funciones del lectory procedimientos de la lectura literaria. México: Siglo XXI.

BOBES NAVES, C. (1992). «El silencio en la literatura». En: El silencio. Compilador Carlos Castilla del Pino. Madrid: Alianza Editorial, pp. 99-123.

BREMOND, C. (1976). «Recherches rhétoriques». En: Communications, 16. París: Seuil.

BRODSKY, J. (1992). Cómo se lee un libro. Trad. Julián Liaño Moral. En: Senderos - Revista de la Biblioteca Nacional de Colombia. 5(24) 383-387.

COLLINGWOOD, R. G. (1993). Los principios del arte. Trad. Horacio Flores Sánchez. México: Fondo de Cultura Económica.

COLODRO, M. (2004). El silencio en la palabra. Aproximaciones a lo innombrable. México: Siglo XXI editores.

CROCE, B. (1997). Estética como ciencia de la expresión y lingüistica general. Trad. Pedro Aullón de Haro y Jesús García Gabaldón. Málaga: Ágora.

CHIRINOS, E. (1998). La morada del silencio. Lima: Fondo de Cultura Económica.

JUARROZ, R. (2008). Poesía Vertical (Antología). España: Visor Libros.

KOVADLOFF, S. (1993). El silencio primordial. Buenos Aires: Emecé Editorial.

MORAÑA, M. (1998). Viaje al silencio. Exploraciones del discurso barroco. México: Universidad Nacional Autónoma de México.

NEHER, A. (1997). El exilio de la palabra. Del silencio bíblico al silencio de Auschwitz. Trad. Alberto Sucasas Peón. Barcelona: Riopiedras. 
NIETZSCHE, F. (1984). Humano, demasiado humano. Buenos Aires: Biblioteca EDAF.

PICARD, M. (1971). El mundo del silencio: ensayo. Trad. Norberto Silvetti Paz. Caracas: Monte Ávila Editores.

PÉREZ PAREJO, R. (2002). Metapoesía y crítica del lenguaje: de la generación de los 50 a los novísimos. Cáceres: Universidad de Extremadura, Servicios de Publicaciones.

(2013). «Qué es silencio y qué no es silencio. Claves de una poética». En: Poesía y silencio. Paradigmas hispánicos del siglo XX y XXI. Christina Johanna Bischoff, Annegret Thiem (eds.). Berlín. Lit. pp. 41-6o.

RIUS, M. (1984). «Prólogo al silencio». En: Enrahonar: Quaderns de filosofia, (7-8). Barcelona: Universitat Autònoma de Barcelona. Departament de Filosofia. pp. 133-139.

RIVAS HERNÁNDEZ, A. De la poética a la teoría de la literatura. (Una introducción). Salamanca: Ediciones Universidad de Salamanca.

SONTAG, S. (1985). «La estética del silencio». En: Estilos radicales: ensayos. Trad. Eduardo Goliogorsky. Barcelona: Muchnik Editores.

STEINER, G. (2006). Lenguajey silencio. Ensayos sobre la literatura, el lenguaje y lo inhumano. Barcelona: Gedisa Editorial.

SUCRE, G. (1985). «La estética del silencio». En: La máscara, la transparencia: ensayos sobre poesía

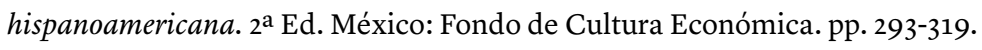

TRUEBLOOD, A. (1958). «El silencio en el Quijote». En: Nueva Revista de Filología Hispánica, XII. México: El Colegio de México, Centro de Estudios Lingüísticos y Literarios. pp. 16o-18o.

VALENTE, J. A. (1979). «Cinco fragmentos para Antoni Tàpies». En: Material memoria. Barcelona: La Gaya Ciencia., pp. 663-674. 